\title{
Occurrence of nonylphenol an endocrine disrupter in Karun River, Khuzestan Province, Iran
}

\author{
A. A. Babaei · A. H. Mahvi $\cdot$ R. Nabizadeh • \\ A. Mesdaghiniai $\cdot$ Z. Nazari $\cdot$ E. Ahmadpour
}

Received: 13 January 2013/Revised: 21 March 2013/Accepted: 6 May 2013/Published online: 29 May 2013

(C) Islamic Azad University (IAU) 2013

\begin{abstract}
The important Iranian Karun River has never been investigated for the presence of potentially endocrinedisrupting chemicals, nonylphenol (NP). In this study, concentrations of NP were measured in water from Karun River and five wastewater discharge points into this river, collected during April to July 2010. The analytes were extracted by solid-phase extraction, and quantitative analyses were performed by HPLC-FLD. NP was detected in water and wastewater samples with $0.17-1.83$ and $15.27-21.79 \mu \mathrm{g} / \mathrm{L}$, respectively. The results showed that the NP content of aqueous phase of all wastewater samples higher than particulate phase, which were detected in the aqueous and particulate phases with mean concentrations of $12.8 \pm 2.4$ and $5.2 \pm 1.2 \mu \mathrm{g} / \mathrm{L}$, respectively. These data suggest that the NP levels in Karun river water are likely attributable to untreated
\end{abstract}

A. A. Babaei

Environmental Technologies Research Center, Ahvaz

Jundishapur University of Medical Sciences, Ahvaz, Iran

A. A. Babaei

Department of Environmental Health Engineering, School of Public Health, Ahvaz Jundishapur University of Medical Sciences, Ahvaz, Iran

A. H. Mahvi - R. Nabizadeh - A. Mesdaghiniai Department of Environmental Health Engineering, School of Public Health, Tehran University of Medical Sciences, Tehran, Iran

Z. Nazari

Department of Toxicology, School of Pharmacy, Ahvaz

Jundishapur University of Medical Sciences, Ahvaz, Iran

E. Ahmadpour $(\square)$

Department of Health, Ahvaz Jundishapur University

of Medical Sciences, Ahvaz, Iran

e-mail: eahmadpour386@gmail.com municipal wastewaters discharged directly into the river. To our knowledge; this is the first study to evaluate NP concentrations in water and wastewater in Iran.

Keywords Nonylphenol - River - Water - Wastewater · Contamination

\section{Introduction}

Public awareness and concern have been growing about exposure to chemicals that have the potential to interfere with the endocrine system (Hecker and Hollert 2011). Nonylphenol (NP) is an endocrine disrupter, toxic, and xenobiotic compound used in the manufacture of antioxidants, lubricating oil additives, pesticides, paints, cosmetics, and the production of NP polyethoxylates nonionic surfactants which is its major use $(65 \%)$ (Ahel et al. 1994a; Uguz et al. 2003). NP shows estrogenic activities at very low concentrations (ppb level), and its feminizing effect on fish is a serious problem in terms of protection of ecological systems (Inumaru et al. 2004; Shue et al. 2009).

The main source of NP in the environment appears to be closely related to the discharge of effluents from wastewater treatment works due to incompletely degradation of its parent compounds, NP ethoxylates mainly by anaerobic digestion (Ahel et al. 1994b; Fries and Püttmann 2004; Langford et al. 2005; Sabik et al. 2003; Mauricio et al. 2006; Zhou et al. 2009; Isobe et al. 2007).

NP has been found with a concentration of as low as $0.6 \mathrm{ng} / \mathrm{L}$ and up to $644 \mu \mathrm{g} / \mathrm{L}$ in river waters (Sole et al. 2000; Soares et al. 2008) and even more than $3,520 \mathrm{mg} / \mathrm{kg}$ in sediments of natural waters (Ahel et al. 1994b). Lou et al. (2012) found that the concentration of NP in the river water ranged from $8.54 \pm 1.23$ (Qiantang River) to 
$65.77 \pm 3.69 \mu \mathrm{g} / \mathrm{L}$ (Tiesha River) using the HPLC-FLD method. According to Tao et al. (2011), the concentrations of NP and OP in Nanming river water ranged from 40 to $1,582 \mathrm{ng} / \mathrm{L}$. The concentration of 4-NP in river water of Germany was reported by Fries and Püttmann (2004), which is ranged from $28 \mathrm{ng} / \mathrm{L}$ (Elbe River) to $1,220 \mathrm{ng} / \mathrm{L}$ (Oder River). Martinez and Peñuela (2012) carried out an analysis of $4 \mathrm{n}-\mathrm{NP}$ in Colombian reservoir water by $\mathrm{GC} /$ MS, where 4n-NP was not found in any of the water samples.

Currently, NP risks have been accepted by EPA and has prepared a guideline for natural water quality that recommends NP concentrations to be below 6.6 and $1.7 \mu \mathrm{g} / \mathrm{L}$, in freshwater and saltwater, respectively (Soares et al. 2008; Brooke and Thursby 2005).

The Karun River is the largest river in Iran in terms of annual discharge $\left(2.2 \times 10^{10} \mathrm{~m}^{3}\right)$. It consists of the Dez River, the Gargar River, and the Shoteit River and flows to the Persian Gulf. It is estimated that $2.1 \times 10^{8}$ and $3.15 \times 10^{8} \mathrm{~m}^{3} /$ annum domestic and industrial wastewaters are discharged into Karun River, respectively. More than $90 \%$ of the wastewaters are not treated effectively prior to discharge. In recent decades, the Karun River contamination is increasingly serious with the explosive increase of population and heavily industrial development. Although many studies focused on the identification of NP in aquatic environments and its side effects around the world, but there has not been any report about NP in Iran. In this study, the NP concentrations in water samples collected from upstream and downstream of Karun River around the Ahwaz metropolis and wastewater discharges into this river were measured.

\section{Materials and methods}

Sampling sites and dates

Sample collections from Karun River water were carried out from April to July 2010 period using a semi-composite sampling procedure. Briefly, water samples were taken at three points in the river cross-section with $6 \mathrm{~h}$ interval in each sampling campaign. Afterward, the samples were mixed together based on river flow and a $3 \mathrm{~L}$ composite sample were taken. Twenty-four-hour composite samples of raw wastewater were taken from discharge points during two sampling campaigns in April and July 2010 from five wastewater discharge points along Karun River on both banks in Ahwaz city area. The geographic location of the

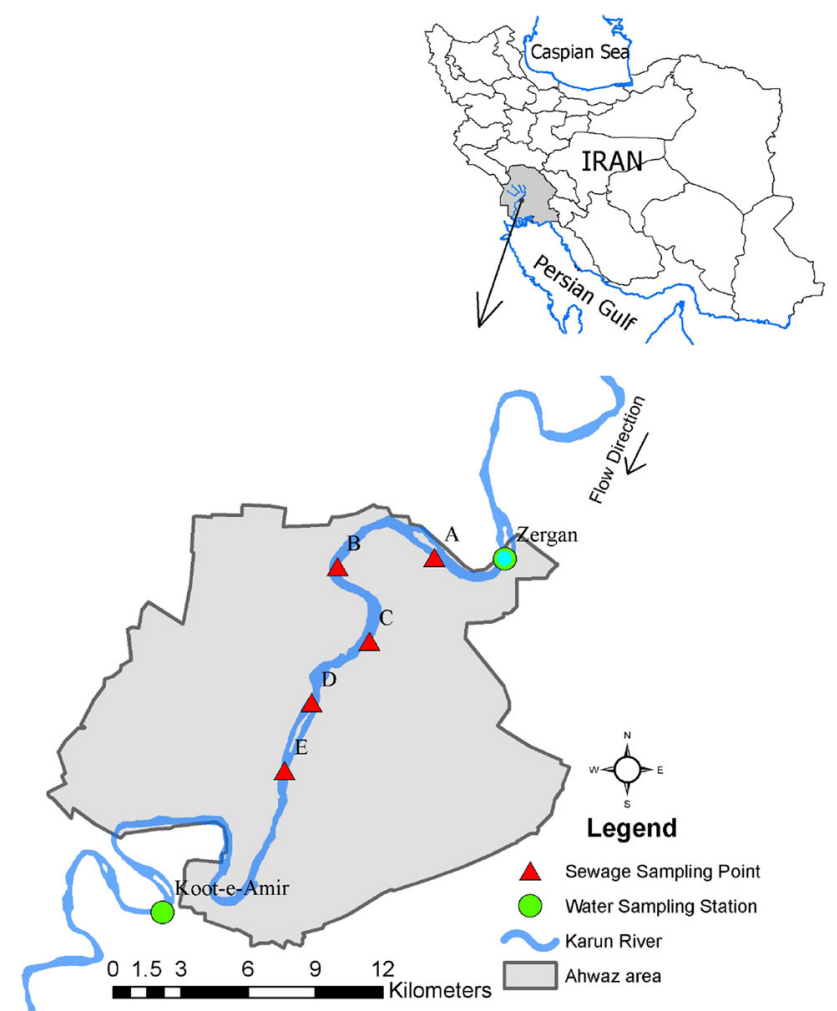

Fig. 1 sampling locations in Karun River and wastewater discharges

Karun River points where water and wastewater samples were collected are shown in Fig. 1. For NP measurements, $3 \mathrm{~L}$ water and $1 \mathrm{~L}$ wastewater samples were collected in amber glass bottle that were previously cleaned and heated to $450{ }^{\circ} \mathrm{C}$ for $8 \mathrm{~h}$. Water and wastewater samples were preserved by the addition of formic acid to $\mathrm{pH} \leq 2$. A total of 28 water samples and 20 wastewater samples were collected, and all samples were directly transported to the laboratory, stored at $4{ }^{\circ} \mathrm{C}$ and analyzed within $24 \mathrm{~h}$ with 3 replicate.

Instruments and chemicals

The Shimadzu 10Avp Series HPLC system (Shimadzu, Japan) coupled with a RF-10A $\mathrm{XL}_{\mathrm{XL}}$ fluoresces detector was employed in this study. We used HPLC grade organic solvents obtained from Merck (Dormstad, Germany). NP $(99.5 \%)$ and $4 \mathrm{n}-\mathrm{NP}-\mathrm{d} 8$ were purchased from Dr. Ehrenstorfer (Audgsburg, Germany). HPLC separations were performed using a Kromasil $100 \quad \mathrm{C} 18$ column $(4.6 \times 150 \mathrm{~mm}, 5 \mu \mathrm{m})$ from Eka Chemicals $\mathrm{AB}$ (Bohus, Sweden) thermostatted at $30{ }^{\circ} \mathrm{C}$, injection volumes of 
$20 \mu \mathrm{l}$, flow rate of $1 \mathrm{~mL} / \mathrm{min}$, and isocratic elution with $40 \%$ water and $60 \%$ acetonitrile $(\mathrm{AcN})$ during $25 \mathrm{~min}$. Analyte was monitored by fluorescence detection $\left(\lambda_{\text {ex }}\right.$ : $222 \mathrm{~nm}, \lambda_{\mathrm{em}}: 305 \mathrm{~nm}$ ) and quantified by external calibration using peak area measurements.

\section{Sample preparation and NP measurements}

Initially, each water and wastewater samples sub-divided into three parts and an appropriate volume of water and wastewater $(100 \mathrm{~mL}$ of wastewater and $1 \mathrm{~L}$ of river water) was filtered through pre-ashed $0.7-\mu \mathrm{m}$-pore-size GF/F filters (Whatman, UK), and for water samples, the retained particulate material and filter were washed with $3 \times 10 \mathrm{~mL}$ of methanol and reduced to $2 \mathrm{~mL}$ which was added to the filtrate. NP was extracted from water and wastewater samples by using SPE C18 cartridge (LH), $500 \mathrm{mg} / 6 \mathrm{~mL}$ (Capital, UK) described by Martinez and Peñuela (2012). Briefly, the filtered water or wastewater samples were loaded onto cartridges previously conditioned with $6 \mathrm{~mL}$ of acetone, $6 \mathrm{~mL}$ of methanol $(\mathrm{MeOH})$, and $6 \mathrm{~mL}$ of ultrapure water acidified to $\mathrm{pH} 2$. Cartridges were washed with ultrapure water, dried under vacuum for $30 \mathrm{~min}$, and analyte was eluted with $3 \times 3 \mathrm{~mL}$ of dichloromethane (DCM). Finally, sample extracts were evaporated to dryness under a nitrogen stream, redissolved in $500 \mu \mathrm{L}$ mobile phase $\mathrm{H}_{2} \mathrm{O} / \mathrm{AcN}$ (40/60) containing $50 \mathrm{ng}$ internal standard, and analyzed by HPLC-FLD. For the determination of NP in the wastewater particulate phase, the retained solids and filters were oven-dried in $30{ }^{\circ} \mathrm{C}$ until constant weight which were placed in Soxhlet apparatus and extracted with $100 \mathrm{~mL}$ methanol for at least $24 \mathrm{~h}$. The extracts were evaporated to $2 \mathrm{~mL}$ and then diluted to $100 \mathrm{~mL}$ with ultrapure water and treated as aqueous phase described previously.

A linearity regression function was set up based on calibration measurement in a range of $25-1,000 \mu \mathrm{g} / \mathrm{L}$. There was a good linearity in the detected range, and correlation coefficients $\left(R^{2}\right)$ were 0.9989 .

Method precision was evaluated in terms of instrumental repeatability and reproducibility of the method. For instrumental and method repeatability, seven successive injections were performed on a standard of $25 \mu \mathrm{g} / \mathrm{L}$ and standard solutions in the matrix at concentration level of $50 \mu \mathrm{g} / \mathrm{L}$, respectively. The $\%$ RSD were satisfactory for the standard and spiked matrix, which were 5.4 and $10.3 \%$, respectively.

The recoveries of target compound in water, wastewater, and particulate phase of wastewater were more than $83 \%$, about 81 and $77 \%$, respectively, indicating acceptable accuracy of the analytical procedure. The obtained method detection level (MDL) ranged from 0.03 (Karun River water samples) to $0.038 \mu \mathrm{g} / \mathrm{L}$ (particulate phase of wastewater samples).

\section{Results and discussion}

Analyses of 28 water and 20 wastewater samples showed that NP is present in Karun River water and wastewater discharges, although its concentrations in Karun River water samples were low (Table 1). The NP level of Karun River water samples ranged between 0.15 and $1.97 \mu \mathrm{g} / \mathrm{L}$, with mean values ( \pm standard deviation) of $0.24 \pm 0.06$ and $1.57 \pm 0.3 \mu \mathrm{g} / \mathrm{L}$ in Zergan (upstream) and Koot-eAmir (downstream) sampling stations, respectively (Fig. 2). The NP level of Koot-e-Amir station ranged from 1.12 to $1.97 \mu \mathrm{g} / \mathrm{L}$ and was higher than Zergan station, which was $0.15-0.32 \mu \mathrm{g} / \mathrm{L}$. This relatively high NP concentration at the Koot-e-Amir might be discharge related and can probably be attributed to raw wastewater discharges and effluents of local wastewater treatment works. The concentrations were comparable with those found in river water of Japan (up to $1.08 \mu \mathrm{g} / \mathrm{L}$ ) (Isobe et al. 2001) and Switzerland (up to $2.25 \mu \mathrm{g} / \mathrm{L}$ ) (Ahel et al. 1994b), but higher than those found in Colombian reservoir water (was not found) (Martinez and Peñuela 2012), rivers of Germany $(0.0007-0.0044 \mu \mathrm{g} / \mathrm{L}) \quad$ (Bester et al. 2001), Korea $(0.0232-0.1876 \mu \mathrm{g} / \mathrm{L}) \quad(\mathrm{Li}$ et al. 2004), and Canada $(<0.092 \mu \mathrm{g} / \mathrm{L})($ Sabik et al. 2003). The water intake of southeast region of Khuzestan Province, with a capacity of $450,000 \mathrm{~m}^{3} /$ day, was located in Koot-e-Amir area, and therefore, NP entering risks into water supply systems is predictable and very important.

Results of the analyses of NP in wastewater samples taken from the five wastewater discharge point along the Karun River in Ahwaz city are summarized in the Table 1 and Fig. 3. In points A-E, NP level of wastewater samples in April and July was ranged from 16.73 to 20.36 and 15.27 to $21.79 \mu \mathrm{g} / \mathrm{L}$, respectively. The maximum concentrations of NP in wastewater samples were observed in $\mathrm{D}$ and $\mathrm{E}$ discharge points with values of 20.36 and $21.79 \mu \mathrm{g} / \mathrm{L}$ in the first and second sampling campaigns, respectively. The results showed that the NP content of aqueous phase of all wastewater samples higher than particulate phase, which were detected in the aqueous and particulate phases with mean concentrations of $12.8 \pm 2.4$ and $5.2 \pm 1.2 \mu \mathrm{g} / \mathrm{L}$, respectively. The concentrations of NP identified in wastewater samples from different discharge points were consistent with the 
Table 1 Occurrence of NP in Karun River water and wastewater discharges (in $\mu \mathrm{g} / \mathrm{L}$ ) included in this study

\begin{tabular}{|c|c|c|c|c|c|c|}
\hline \multirow[t]{2}{*}{ Sampling points } & & \multicolumn{4}{|c|}{ Sampling campaigns (2010) } & \multirow[t]{2}{*}{ Mean } \\
\hline & & April & May & Jun & July & \\
\hline \multirow[t]{2}{*}{ Karun River } & Zergan & $0.17 \pm 0.02$ & $0.28 \pm 0.04$ & $0.29 \pm 0.04$ & $0.23 \pm 0.02$ & $0.24 \pm 0.06$ \\
\hline & Koot-e-Amir & $1.32 \pm 0.22$ & $1.70 \pm 0.22$ & $1.83 \pm 0.19$ & $1.59 \pm 0.23$ & $1.57 \pm 0.30$ \\
\hline \multirow[t]{6}{*}{ Wastewater discharges } & A & $18.54 \pm 2.51$ & - & - & $15.85 \pm 1.99$ & $17.20 \pm 2.51$ \\
\hline & B & $17.47 \pm 1.14$ & - & - & $17.77 \pm 2.30$ & $17.62 \pm 1.63$ \\
\hline & $\mathrm{C}$ & $19.28 \pm 0.46$ & - & - & $15.27 \pm 2.13$ & $17.27 \pm 2.60$ \\
\hline & $\mathrm{D}$ & $20.36 \pm 0.92$ & - & - & $17.08 \pm 0.85$ & $18.72 \pm 1.97$ \\
\hline & $\mathrm{E}$ & $16.73 \pm 1.99$ & - & - & $21.79 \pm 1.58$ & $19.26 \pm 3.20$ \\
\hline & Mean & $18.48 \pm 1.89$ & & & $17.55 \pm 2.84$ & $18.01 \pm 2.42$ \\
\hline
\end{tabular}

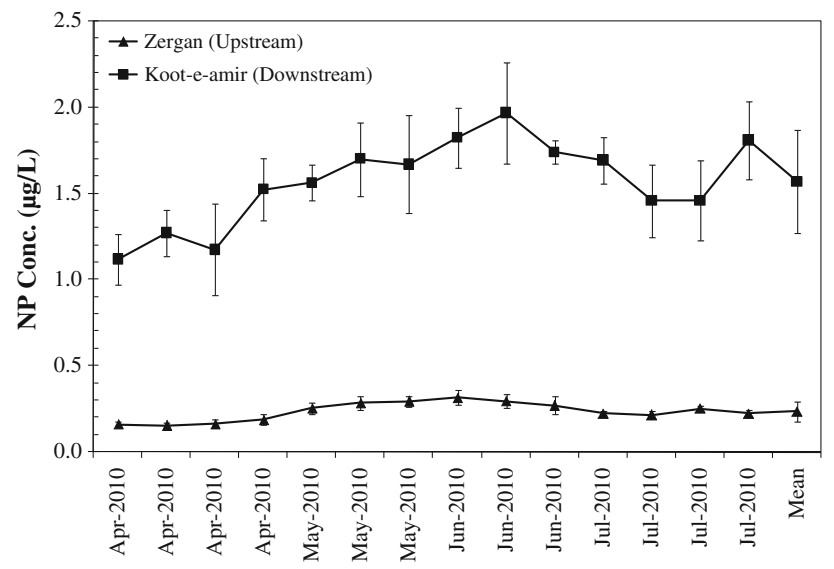

Fig. 2 Concentrations of NP in water samples from the Karun River

reported levels in Italy (Petrovic and Barceló 2004) and China (Lian et al. 2009), but were at high level compared to those observed in the European and Asian countries, such as Spain $(<1.5 \mu \mathrm{g} / \mathrm{L})$ (Farre et al. 2002), UK $(<0.02-0.1 \mu \mathrm{g} / \mathrm{L})($ Sheahan et al. 2002), Japan $(0.1-0.9$ $\mu \mathrm{g} / \mathrm{L})$ (Nakada et al. 2006), and China (0.015-0.101 $\mu \mathrm{g} / \mathrm{L})$ (Zhou et al. 2009), indicating that the contamination in Ahwaz seemed heavy than abroad, probably due to high consumption of NPnEOs surfactants or poor sewer conditions.

\section{Conclusion}

NP concentrations in Karun River water and wastewater discharges of Ahwaz city were surveyed during April to July 2010. This study showed that the NP was ubiquitous in

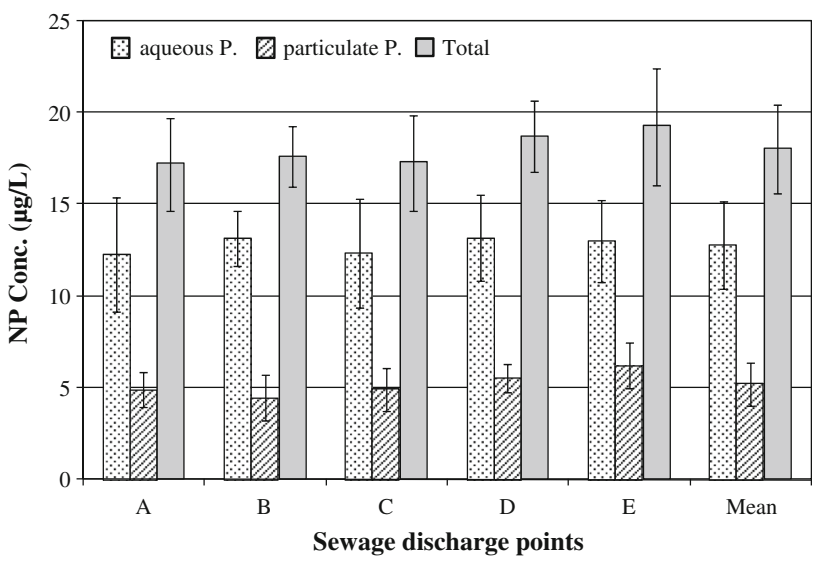

Fig. 3 NP levels of aqueous and particulate phase in different wastewater discharge points included in this study

Karun River water and wastewater discharges. At downstream of Ahwaz city (Koot-e-Amir hydrometric station), total NP concentrations of Karun River water were increased by a factor of 6.65 compared to upstream of Ahwaz city (Zergan hydrometric station). In Ahwaz, only a minor fraction (about $10 \%$ ) of wastewater can be treated before discharging. As Ahwaz is a densely populated city, NP detected in Karun River water is probably closely related to the domestic activities of urban dwellers.

The detection of NP in the all wastewater discharges suggests anaerobic transformation of its parent compounds, NPnEOs, in the sanitary sewers due to septic conditions in Ahwaz sewer and low dissolved oxygen levels in raw wastewaters. On the one hand, about $2.1 \times 10^{8} \mathrm{~m}^{3} /$ annum of untreated domestic wastewater effluent into Karun River could discharge about $3,780 \mathrm{~kg} / \mathrm{year}$ of potentially endocrine-disrupting chemicals (EDCs), NP. 
With the importance of Karun River as main water supply source in Khuzestan Province and a place for living of biota, the information on occurrence and fate of EDCs such as NP is particularly important because of their potential effects on the aquatic biota. Future research on the temporal and spatial variation of the EDCs such as alkylphenol ethoxylates and their derivatives in water body and especially sediments of Karun River and other water resources in Iran are needed and recommended. Due to the significant contributions of NP to the estrogenic activities, future efforts should be focused on its impacts on biota in Karun River and other water resources in Iran.

Acknowledgments This research was financially supported by the Khuzestan Water and Power Authority (Contract No. 88-01-02-034) and Tehran University of Medical Sciences (TUMS). We gratefully appreciate the technical assistance of NP analysis by HPLC-FLD from Dr. Abdolazim Behfar affiliated with the Faculty of Pharmacy, Jundishapur University of medical sciences, Ahwaz, Iran.

\section{References}

Ahel M, Giger W, Koch M (1994a) Behaviour of alkylphenol polyethoxylate surfactants in the aquatic environment-I. Occurrence and transformation in sewage treatment. Water Res 28(5):1131-1142

Ahel M, Giger W, Schaffner C (1994b) Behaviour of alkylphenol polyethoxylate surfactants in the aquatic environment-II. Occurrence and transformation in rivers. Water Res 28(5): $1143-1152$

Bester K, Theobald N, Schroder HF (2001) Nonylphenols, nonylphenol-ethoxylates, linear alkylbenzenesulfonates (LAS) and bis (4-chlorophenyl)-sulfone in the German Bight of the North Sea. Chemosphere 45(6-7):817-826

Brooke L, Thursby G (2005) Ambient aquatic life water quality criteria for nonylphenol. Report for the United States EPA, Office of Water, Office of Science and Technology, Washington

Farre M, Kloter G, Petrovic M, Alonso MC, de Alda MJL, Barcelo D (2002) Identification of toxic compounds in wastewater treatment plants during a field experiment. Anal Chim Acta 456(1):19-30. doi:10.1016/S0003-2670(01)00908-4

Fries E, Püttmann W (2004) Occurrence of 4-Nonylphenol in rain and snow. Atmos Environ 38(13):2013-2016

Hecker M, Hollert H (2011) Endocrine disruptor screening: regulatory perspectives and needs. Environ Sci Eur 23(1):1-14. doi: 10.1186/2190-4715-23-15

Inumaru K, Murashima M, Kasahara T, Yamanaka S (2004) Enhanced photocatalytic decomposition of 4-nonylphenol by surface-organografted $\mathrm{TiO} 2$ : a combination of molecular selective adsorption and photocatalysis. Appl Catal B 52(4):275-280
Isobe T, Nishiyama H, Nakashima A, Takada H (2001) Distribution and behavior of nonylphenol, octylphenol, and nonylphenol monoethoxylate in Tokyo metropolitan area: their association with aquatic particles and sedimentary distributions. Environ Sci Technol 35(6):1041-1049

Isobe T, Takada $\mathrm{H}$, Kanai M, Tsutsumi S, Isobe $\mathrm{K}$, Boonyatumanond R, Zakaria M (2007) Distribution of polycyclic aromatic hydrocarbons (PAHs) and phenolic endocrine disrupting chemicals in South and Southeast Asian mussels. Environ Monit Assess 135(1):423-440

Langford KH, Scrimshaw MD, Birkett JW, Lester JN (2005) Degradation of nonylphenolic surfactants in activated sludge batch tests. Water Res 39(5):870-876

Li D, Kim M, Shim WJ, Yim UH, Oh J-R, Kwon Y-J (2004) Seasonal flux of nonylphenol in Han River, Korea. Chemosphere 56(1):1-6

Lian J, Liu JX, Wei YS (2009) Fate of nonylphenol polyethoxylates and their metabolites in four Beijing wastewater treatment plants. Sci Total Environ 407(14):4261-4268. doi:10.1016/j. scitotenv.2009.03.022

Lou LP, Cheng GH, Yang Q, Xu XH, Hu BL, Chen YX (2012) Development of a novel solid-phase extraction element for the detection of nonylphenol in the surface water of Hangzhou. J Environ Monit 14(2):517-523. doi:10.1039/C1em10731c

Mauricio R, Diniz M, Petrovic M, Amaral L, Peres I, Barcelo D, Santana F (2006) A characterization of selected endocrine disruptor compounds in a Portuguese wastewater treatment plant. Environ Monit Assess 118(1-3):75-87. doi:10.1007/ s10661-006-0986-8

Nakada N, Tanishima T, Shinohara H, Kiri K, Takada H (2006) Pharmaceutical chemicals and endocrine disrupters in municipal wastewater in Tokyo and their removal during activated sludge treatment. Water Res 40(17):3297-3303

Petrovic M, Barceló D (2004) Fate and removal of surfactants and related compounds in wastewaters and sludges. In: The Handbook of Environmental Chemistry, vol 5 Part I. Springer-Verlag Berlin Heidelberg, pp 1-28

Sabik H, Gagne F, Blaise C, Marcogliese DJ, Jeannot R (2003) Occurrence of alkylphenol polyethoxylates in the St. Lawrence River and their bioconcentration by mussels (Elliptio complanata). Chemosphere 51 (5):349-356. doi:Doi 10.1016/S00456535(02)00862-7

Sheahan DA, Brighty GC, Daniel M, Kirby SJ, Hurst MR, Kennedy J, Morris S, Routledge EJ, Sumpter JP, Waldock MJ (2002) Estrogenic activity measured in a sewage treatment works treating 5 industrial inputs containing high concentrations of alkylphenolic compounds-a case study. Environ Toxicol Chem 21(3):507-514

Shue M-F, Chen F-A, Chen T-C (2009) Total estrogenic activity and nonylphenol concentration in the Donggang River, Taiwan. Environmental Monitoring and Assessment. http://dx.doi.org/10. 1007/s10661-009-1093-4

Soares A, Guieysse B, Jefferson B, Cartmell E, Lester JN (2008) Nonylphenol in the environment: a critical review on occurrence, fate, toxicity and treatment in wastewaters. Environ Int 34(7):1033-1049. doi:10.1016/j.envint.2008.01.004

Sole M, Lopez de Alda MJ, Castillo M, Porte C, Ladegaard-Pedersen K, Barcelo D (2000) Estrogenicity determination in sewage 
treatment plants and surface waters from Catalonian area (NE Spain). Environ Sci Technol 34:5076-5083

Uguz C, Togan I, Eroglu Y, Tabak I, Zengin M, Iscan M (2003)

Alkylphenol concentrations in two rivers of Turkey. Environ Toxicol Pharmacol 14(1-2):87-88
Zhou H, Huang X, Wang X, Zhi X, Yang C, Wen X, Wang Q, Tsuno H, Tanaka H (2009) Behaviour of selected endocrine-disrupting chemicals in three sewage treatment plants of Beijing, China. Environ Monit Assess 161(1):107-121 